\title{
DEBRIS-INFLUENCED SLIDING LAWS AND BASAL DEBRIS BALANCE
}

\author{
By E.M. SHOEMAKER \\ (Department of Mathematics and Statistics, Simon Fraser University, \\ Burnaby, British Columbia V5A 1S6, Canada)
}

ABSTRACT. In order to determine the effect of basal debris drag as a component in a sliding law, it is necessary to know the basal debris concentration. Does, for example, this debris concentration exhibit uniformity, in an average sense, across a valley? What effect does a localized region of high quarryability have on basal debris concentration down-stream? The analysis presented here suggests that, for the case of sparse debris, debris concentration tends to be uniform over the entire bed. Consequently, the debris-drag term in a sliding law will also tend to be uniform.

In order to reach the above conclusions, it is necessary to consider debris balance, the balance of the quarrying, abrasion, and debris-flushing rates. This entails proposing and testing quarrying and flushing laws, since these laws have not been previously proposed. It is concluded that the quarrying, flushing, and erosion rates depend weakly on the sliding velocity. Furthermore, the abrasion rate is negligible compared to the quarrying rate. (This conclusion depends partially on the definition of abrasion.) The quarrying rate also depends on other factors such as the effective pressure-pressure-fluctuation mechanism; the cross-valley dependency of this mechanism is investigated. The flushing rate is found to depend on the ratio, $\mathrm{N}$-channel area/bed area, and on average $\mathrm{N}$-channel diameter.

RÉsumé. Lois de glissement en présence de débris sous-glaciaires et bilan des débris. Si l'on veut déterminer l'influence de la traînée due aux débris rocheux sur la loi de glissement, on doit donnaitre la concentration de la glace basale en débris. Cette concentration est-elle, par exemple, en moyenne, uniforme dans une vallée? Quel effet peut avoir une région facile a excaver sur la concentration en débris à l'aval? L'analyse que nous présentons ici suggère que, dans le cas d'une faible concentration, celle-ci tend à être uniforme sur tout le lit. Ainsi le terme de la loi de glissement prenant en compte la traînée due aux débris tendra lui aussi à être uniforme.

Pour arriver aux conclusions ci-dessus on doit examiner le bilan des débris, le bilan de débitage, l'abrasion et la vitesse d'élimination des débris. Cela nous amène à proposer et à tester des lois régissant l'abbatage et l'élimination des débris car aucune loi concernant ces

\section{INTRODUCTION}

Hallet (1979[a], 1981) considered a linear sliding relation in which the contribution to sliding resistance due to rock-rock friction from sparse ice-entrained debris was included. Assuming that Hallet's model adequately evaluates the contribution of debris to sliding resistance, there is at least one important implication. The ratio (sliding resistance due to debris/total sliding resistance) can assume values up to 0.8 for low roughness $r^{*}=0.01$ and even at $r^{*}=0.05$ the ratio can be 0.5 . This follows from Hallet (1981, fig. 2) and both results apply at the condition where $40 \%$ of the phénomènes n'a été proposée auparavant. On en conclut que les vitesses d'abbatage, d'élimination et d'érosion dépendent peu de la vitesse de glissement. En outre l'abrasion est négligeable comparée à l'abbatage. (Cette conclusion dépend du sens que l'on donne en terme abrasion.) La vitesse d'abbatage sous-glaciaire dépend aussi d'autres facteurs (pression effective - fluctuations de pression) et l'on examine les variations latérales de ce mécanisme. La vitesse d'élimination des débris dépend du rapport surface des chenaux/surface du lit et du diamètre moyen des chenaux sous-glaciaires.

ZUSAMMENFASSUNG. Schuttabhängige Gleitgesetze und Schuttbilanz am Untergrund. Zur Bestimmung der Wirkung der Hemmung durch Schutt am Untergrund als Komponente in einem Gleitgesetz ist die Kenntnis der Schuttkonzentration am Untergrund erforderlich. Weist zum Beispiel diese Schuttkonzentration quer zu einem Tal mittlere Gleichmassigkeit auf? Welche Wirkung hat ein begrenztes Gebiet hoher Brüchigkeit auf die Schuttkonzentration am Untergrund stromabwărts? Die hier vorgelegte Analyse deutet darauf hin, dass im falle spärlichen Schuttes dessen Konzentration zur Gleichmăssigkeit über das ganze Bett hin neigt. Folglich tendiert der Ausdruck für die Schutthemmung in einem Gleitgesetz ebenfalls zur Gleichförmigkeit.

Um zu den genannten Folgerungen zu kommen, muss die Schuttbilanz betrachtet werden, nămlich die Bilanz von Ausbruch, Abrasion und Abfuhr des Schuttes. Dies führt zum Vorschlag und zur Erprobung von Ausbruchs- und Abfuhrgesetzen, die bisher nicht in Erwägung gezogen worden sind. Es lăsst sich zeigen, dass sowohl die Ausbruchs- wie die Abfuhr- und die Erosionsraten nur schwach von der Gleitgeschwindigkeit abhăngen. Weiter ist die Abrasionsrate gegenüber der Ausbruchsrate vernachlăssigbar. (Diese Folgerung hängt teilweise von der Definition für Abrasion ab.) Die Ausbrucdhsrate hängt von noch anderen Faktoren wie dem Mechanismus zwischen effektivem Druck und Druckschwankungen ab; der Verlauf dieses Mechanismus quer zum Tal wird untersucht. für die Abfuhrrate ergibt sich eine Abhängigkeit vom Flächenverhältnis zwischen $\mathrm{N}-\mathrm{Kanălen}$ und Untergrund sowie vom mittleren Durchmesser der N-Kanäle.

bed is effectively covered by debris. This debrisconcentration value is perhaps too high for a sparse debris model. Nevertheless, it is clear that the debris-drag term is likely to be important to sliding resistance.

Hallet's linear sliding relation can be written as

$$
\tau_{\mathrm{b}}=\xi u_{u_{\mathrm{b}}}+\mu_{c} F
$$

where $\xi \equiv$ a bed roughness factor, $\eta \equiv$ effective viscosity, $u_{\mathrm{b}} \equiv$ ice-sliding velocity, $\mu \equiv$ coefficient or rock-rock friction, $c \equiv$ projected area of basal rock fragments/unit 
basal area, and $F \equiv$ average rock-fragment force/projected area of average fragment. Equation (1) is not intended as a local sliding law but is assumed to be averaged over an area approximately the square of the average ice thickness.

For the linear model of Equation (1), Hallet (1981) argued that, if $v_{n}$ (the ice velocity normal to the bed) is positive (ice-bedrock convergence), $F$ is proportional to $v_{n}$, since there is a close relationship between $v_{n}$ and the speed at which the average rock is pushed into the ice by the rock-rock contact force. If $v_{n}$ is zero or negative, $F$ is set equal to zero. There are three contributions to $v_{\mathrm{n}}$ : uniform melting due to geothermal heat and sliding friction, regelation melting, and straining normal to the interface. A comparison of Hallet (1979[a], fig. 2) and Hallet (1981, fig. 2) demonstrates that, normally, regelation melting plus straining on stoss slopes dominates uniform melting. Furthermore, debris drag is important only on stoss slopes and is otherwise neglected. On stoss slopes $v_{n}$ is proportional to $u_{\mathrm{b}}$ (Hallet, 1981). Finallly, the tangential component of velocity of the embedded debris fragments relative to the ice may be neglected so that particle sliding velocity is synonymous with $u_{\mathrm{b}}$.

Thus, if the contribution of uniform basal melting to $v_{\mathrm{n}}$ is neglected, Equation (1) can be written as

$$
\tau_{\mathrm{b}}=K_{1} u_{\mathrm{b}}+K_{2} c u_{\mathrm{b}}
$$

where $K_{1}=\xi \eta$. Parameter $K_{2}$ involves a spatial average of positive values of $v_{\mathrm{n}}$. A relationship between $\tau_{\mathrm{b}}$ and $u_{\mathrm{b}}$ which includes $c$ will be called a debris-influenced sliding law, whereas the more familiar relationship $\tau_{\mathrm{b}}=g\left(u_{\mathrm{b}}\right)$ will be called a sliding law. Because $c$ can depend upon $u_{b}$ and/or $\tau_{b}, c$ is not really an assigned parameter but rather a dependent variable. Conditions must be found to determine or prescribe $c$ and our initial considerations are aimed at this problem.

Although the investigations here are restricted to the linearized law in Equation (1'), the procedures developed can be applied, for example, to non-linear laws of the class

$$
\tau_{\mathrm{b}}=K_{3} u_{\mathrm{b}}^{m_{1}}+K_{4} c u_{\mathrm{b}}^{m_{2}}
$$

In fact, the case $m_{1}=1 / 2, m_{2}=1 / 6$ has been investigated and qualitatively agrees with the linear case. (In a paper in preparation, Hallet extends Equation (1) to a generalization of a Weertman $(1957,1964)$ type debris sliding law. He considers two limiting cases, with large and small debris fragments, respectively, and obtains relations of the form given in Equation (2). Constants $m_{1}=1 / 2, \quad m_{2}=1 / 6$ correspond to the large fragment case.)

In what follows, discrete processes will be replaced by continuous average processes. Let us consider some aspects of the discrete processes of quarrying, abrasion, and debris flushing as these processes apply to individual rock fragments. There are several paths which fragments can take before becoming entrained in ice at the base. (a) Debris can be (locally) detached from bedrock and very shortly engulfed by ice. (b) Debris can enter at the margins, or (c) through the moulin-crevasse system, and (d) it can be lowered to the bed by basal melting. We will assume that once debris enters the main fluvial system it is flushed and does not re-appear as ice-entrained debris at the base. Because debris in transport in the fluvial system has no direct bearing on Equation (1'), path (c) may be assumed to have no effect on the model and need not be considered. The contribution of path (d) can be neglected, first, because the normal rate of basal melting is of the order $10 \mathrm{~cm} / \mathrm{a}$. Secondly, at basal water channels where the melt rate is much higher, we assume that debris being lowered to the base will melt into the channels and not be deposited at the base. (There is a tacit assumption made here and elsewhere that, either there is no layer of debris-rich ice near the base or, if there is, that its debris concentration is timeinvariant.) Path (b) can be important and can distort debris balance near the margins. Path (a) is assumed to dominate in producing entrained basal debris, except possibly near margins.
A clast entrained in ice at the base is assumed to follow a basal ice stream line while being subjected to fragmentation and abrasion, and, possibly, to eventual flushing at, for example, a basal channel. In the case of debris flour, flushing can occur via a water film or small feeder channel.

\section{CONSTANT-STATE, AXIALLY INDEPENDENT SLIDING LAWS}

The key consideration in determining $c$ is debris mass balance. This involves modelling or, at least a qualitative understanding of, the processes of quarrying abrasion and fluvial flushing of debris. In general, $c$ is a function of time as well as of position. We shall not consider the time variation of any quantities. Spatial variations in $c$ may result from changes in quarryability, attritivity, fluvial flushing of debris, and pressure fluctuations, as well as from changes in bedrock slope, accumulation, etc. All of these parameters will be held constant along stream lines in our initial consideration of axial-independent flow.

Abrasion quarrying and debris flushing are discontinuous processes whose averages will be modelled here as continuous processes. The axial-independent assumption implies that at all points along a stream line a constant average value of $c$ is maintained by continuous abrasion, quarrying, and flushing. Debris flushing by major water conduits is assumed to be averaged spatially. The model does not apply near the margin, where erosion by frost action might be important and a large fraction of the debris might originate from external sources.

We assume that, corresponding to a linear viscous material and the linear sliding relation in Equation (1'), the abrasion rate of the entrained abrasion tools can be represented by

$$
\dot{a}=k_{\mathrm{a}} c u_{\mathrm{b}}^{2}
$$

where $k_{\mathrm{a}}$ is an attritivity coefficient and may be a function of stream-line position. Equation (3) follows from Hallet (1981, equations (5), (2), and (3)), who used it within the context of bed abrasion and is consistent with Metcalf (1979). It is convenient, for debris-balance considerations, to express $\dot{a}$ in Equation (3) in units of (thickness/time). That is, we think of the abrasion process as a uniform process. The abrasion tools are replaced by a continuous slab of rock with the same mass distribution, in an average sense, in units of mass/unit areas as the basal debris. (Note that ice is not part of debris-balance considerations and is therefore not part of the debris slab.) The tool-abrasion process is now thought of as acting on the continuous debris slab and the attritivity coefficient $k_{\mathrm{a}}$ in Equation (3) is defined to be consistent with this model.

Equation (3) measures abrasion rate by grinding, a term which is difficult to define. We believe it is consistent to define the tool-abrasion rate as the rate (length/time) at which the debris slab is turned into debris flour. Thus, breaking a clast into small pieces does not constitute abrasion if no debris flour is created. The smaller clasts remain as debris tools, capable of abrading bedrock, and therefore are still considered part of the debris slab. We shall somewhat arbitrarily define debris flour as particles less than $60 \mu \mathrm{m}$ in diameter. Thus debris flour is defined as silt. It will later be convenient to assume that debris flour is not entrained in the ice but is continuously flushed away. Therefore, our definition of debris flour must be consistent with field observations involving entrained debris flour. Vivian (1980) observed at several sites that no particles less than $200 \mu \mathrm{m}$ were entrained in basal ice and therefore must be continuously flushed through the water film. On the other hand, Hooke and others (1985) observed entrained silt beneath Bondhusbreen. Note, however, that Vivian was looking at particles entrained at the ice surface, whereas Hooke and others were investigating a debris layer approximately $2 \mathrm{~m}$ thick. The value $60 \mu \mathrm{m}$ corresponds to the boundary between silt and very fine sand, but it is also representative of film thicknesses which are thought to be of order 10-100 $\mu \mathrm{m}$ (Hallet, 1979[b]). Thus, debris flour as defined here could be flushed by water films. (It will become apparent that the model is not sensitive to the 
definition of debris flour, provided that the definition does not affect the assumption that the abrasion rate is much smaller than the quarrying rate.)

Turning to a consideration of bedrock erosion, the quarrying rate of bedrock (units of length/time) is defined as the erosion rate minus the abrasion rate, i.e. minus the rate of creation of debris flour from bedrock. Note that fluvial wear which results in debris flour will not enter in debris-balance considerations; fluvial plucking involving particles of any size greater than debris flour may be included in quarrying. By defining abrasion and quarrying in this way, we avoid conflicting definitions (see general discussion in Journal of Glaciology, Vol. 23, No. 89, p. 381-400).

Along a stream line in axial-independent flow, debris is created by quarrying at rate $\dot{q}$ (length normal to the bed/unit time). Debris is simultaneously incorporated into ice (the debris slab) at the same rate. (We neglect the deposition rate of debris into cavities as well as the flushing of debris before it is incorporated into the ice The latter term could be important to debris balance and should be considered in later models.) In addition, bedrock is abraded at rate $\dot{a}_{\mathrm{b}}$ so that the bed-erosion rate is $\dot{e}=\dot{q}+\dot{a}_{\mathrm{b}}$.

To obtain a relation between $\dot{q}$ and $\dot{a}$, consider the mass balance of the debris slab. We shall assume that $\dot{a}=\dot{a}_{\mathrm{b}}$, as suggested by Boulton (1979), so that the debris slab and bedrock are abraded at the same rate. (Any experimental evidence suggesting another relationship can be easily incorporated but the results are not sensitive to the relative abrasion rates.) We will assume that debris flour is not entrained in the ice but is continuously flushed away. This assumption is suggested by Vivian's (1980) observations, as previously discussed. (The alternative assumption, that debris flour is entrained in the ice, could be made. This would increase the abrasion rate of bedrock but not of the debris slab, i.e. entrained debris flour can abrade bedrock but (by definition) entrained debris flour cannot be further abraded.) Thus entrained rock fragments are reduced in size by fracturing or abrasion. Once a fragment reaches the state of debris flour, or a diameter less than $60 \mu \mathrm{m}$, while part of the debris slab, it is immediately flushed away and does not participate further in the abrasion process.

It is important to note that we do not allow for the possibility that, if a layer of debris-rich ice is present above the bed, the debris content of this layer changes with time. The debris slab consists only of debris at the icebedrock interface and debris "time-varying storage" above the interface is assumed not to occur.

For the debris slab to retain a constant thickness along a stream line, debris other than debris flour must be flushed away at rate $\dot{q}-\dot{a}$. We will discuss the flushing mechanism later. Now, along a stream line in axialindependent flow $\dot{q}$ and $\dot{a}$ are constant and must maintain a fixed ratio. Thus,

$$
\dot{q}=f_{\mathrm{f}} \dot{a}
$$

where the proportionality factor $f_{\mathrm{f}} \geqslant 1$ may depend on the stream-line position for a given valley in axial-independent flow. Factor $f_{\mathrm{f}}$ will be called the fluvial flushing factor and its physical meaning and functional dependence will be examined later.

To summarize, the erosion rate of bedrock is $\dot{e}=\dot{q}+\dot{a}$ and can now be represented in either of two forms

$$
\dot{e}=\left(1+f_{\mathrm{f}}\right) \dot{a}=\left(1+\frac{1}{f_{\mathrm{f}}}\right) \dot{q}
$$

(Fluvial wear is not considered explicitly in Equation (5), although fluvial quarrying may be considered part of $\dot{q}$ through Equation (6b).) The debris slab is maintained at constant thickness along a stream line by a balance of: entrainment rate $\dot{q}$ or $f_{\mathrm{f}} \dot{a}$, abrasion rate $\dot{a}$ or $\dot{q} / f_{\mathrm{f}}$, the same quantity being simultaneously flushed as debris flour, and debris-flushing rate $\left(f_{\mathrm{f}}-1\right) \dot{a}$ or $\left(1-1 / f_{\mathrm{f}}\right) \dot{q}$. We have made a distinction between the flushing of debris flour, which is assumed to take place with total efficiency under all conditions, and "debris flushing"; the latter process is not totally efficient because debris is entrained. This process must be modelled.

Considerations of bed erosion or debris mass balance require that a quarrying law be introduced, but none exists, although Röthlisberger and Iken (1981) have investigated a mechanism which is highly dependent on fluctuations in water pressure and is aided by a low basal effective pressure. Perhaps the simplest quarrying laws would be of the forms

$$
\begin{aligned}
& \dot{q}=k_{\mathrm{q}}^{\prime} \tau_{\mathrm{b}}{ }^{8}, \\
& \dot{q}=k_{\mathrm{q}} u_{\mathrm{b}} \gamma
\end{aligned}
$$

where $k_{\mathrm{q}}^{\prime}$ and $k_{\mathrm{q}}$ depend on fracture properties and degree of jointing. Because $\dot{q}$ might also depend on effective pressure, water-pressure fluctuations, or other factors, these dependencies must also be incorporated into $k_{\mathrm{q}}^{\prime}$ and $k_{\mathrm{q}}$ Constant exponents $\delta$ and $y$ are to be determined. The first law will not be investigated here, since it has been found to be fundamentally deficient. The second law is suggested by the belief that quarrying should be enhanced by large contact stresses. Contact stresses increase as contact areas decrease, i.e. flow separation increases. For fixed effective pressure, contact stresses should therefore increase with $u_{\mathrm{b}}$. Of course, reducing the bed effective pressure also reduces contact areas. yields

Substitution of Equations (3) and (6b) into Equation (4)

$$
k_{\mathrm{q}} u_{\mathrm{b}}^{\gamma}=f_{\mathrm{f}} k_{\mathrm{a}} c u_{\mathrm{b}}^{2} .
$$

Equation (7) is a relation among many parameters which are very poorly understood. However, we shall find it useful later in considering various examples in axial-independent flow.

We write Equations ( $\left.1^{\prime}\right)$ and (7) in dimensionless form

$$
\begin{gathered}
T_{\mathrm{b}}=r K_{1}^{*} U_{\mathrm{b}}+(1-\mathrm{r}) K_{2}^{*} C U_{\mathrm{b}}, \\
K_{\mathrm{q}}^{*} U_{\mathrm{b}}^{\gamma}=F_{\mathrm{f}}^{*} K_{\mathrm{a}}^{*} C U_{\mathrm{b}}^{2} .
\end{gathered}
$$

Here, variables $T_{\mathrm{b}}, U_{\mathrm{b}}, C$ are the ratios of the original variable in a fixed reference state to the same variable in another state. (For example, in considering cross-valley relationships in axial-independent flow for a given valley, the reference state will be taken to be on the center-line stream line.) Thus, $T_{\mathrm{b}}=U_{\mathrm{b}}=C=1$ in the reference state. Coefficients $K_{1}^{*}, K_{2}^{*}, F_{\mathrm{f}}^{*}, K_{\mathrm{q}}^{*}$, and $K_{\mathrm{a}}^{*}$ are similarly defined ratios of the original coefficients and are unity in the reference state. Coefficient $r$ is the ratio in the reference state of basal resistance due to flow and regelation over the uneven bed divided by total resistance.

Elimination of $C$ from Equation (1") by using Equation ( $\left.7^{\prime}\right)$ gives an alternative form of the debris-influenced sliding law

$$
T_{\mathrm{b}}=r K_{1}^{*} U_{\mathrm{b}}+(1-r) \frac{K_{2}^{*} K_{\mathrm{q}}^{*}}{F_{\mathrm{f}}^{*} K_{\mathrm{a}}^{*}} U_{\mathrm{b}}^{\gamma-1}
$$

where Equation $\left(7^{\prime}\right)$ determines $C$ as

$$
C=\frac{K_{\mathrm{q}}^{*} U_{\mathrm{b}}^{\gamma-2}}{F_{\mathrm{f}}^{*} K_{\mathrm{a}}^{*}}
$$

\section{Parameter ranges and relationships}

Let us consider what is known of the various parameters in Equations (1"), ( $\left.7^{\prime}\right),(8)$, and (9). $K_{1}$ depends on roughness and effective pressure $P_{\mathrm{E}}$ at the bed. Roughness will be assumed uniform for a particular bed. There are no data on transverse variation in $P_{\mathrm{E}}$. Theoretical studies (Bindschadler, 1983) indicate that $P_{\mathrm{E}}$ could be 
relatively high at the center under conditions of low channel pressures and approximately uniform under conditions of high channel pressures. Bindschadler's model was based on closed channel flow of a network of R-channels feeding into a central channel. Recent theoretical studies of Hooke (1984) indicate that, where beds slope downward in the direction of channel flow, channel pressures could be much lower, on average, than previously thought because open-channel flow is pervasive. Under conditions of openchannel flow, $P_{E}$ would be much higher under thick ice than near the margins. Therefore, there is reason for assuming that the time-averaged $P_{\mathrm{E}}$ (and therefore $K_{1}$ ) decreases from center to margin. Lliboutry (1979) estimated that pressure changes can alter $K_{1}$ by a factor of about 2 . Presumably, average transverse variations would be less than this. It is clear from Equation (1") that, as $K_{1}$ decreases, the debris-drag term becomes relatively more important.

$K_{2}$ depends on the friction coefficient, average particle size, and transition radius (Hallet, 1981). All of these will be assumed uniform for a particular valley so that $K_{2}^{*} \equiv 1$ in such an application.

Similarly, attritivity will be assumed uniform across a particular valley so that $K_{a}^{*} \equiv 1$ for this case. The range of parameter $r$ corresponds to the range of applicability of the sparse debris model. As previously noted, Hallet (1981, fig. 2) indicated an approximate range $0.2<r \leqslant 1.0$

By definition, $f_{\mathrm{f}} \geqslant 1$ and we can argue that $f_{\mathrm{f}} \gg 1$. We emphasize that rock fragmentation has not been included with abrasion unless this results in debris flour. Abrasion is rock-rock grinding which results in debris flour, fine enough to be washed away by a thick water film or very minor channel. Goldthwaite (see general discussion in Journal of Glaciology, Vol. 23, No. 89, p. 387) referred to a case where average $\dot{q} / \dot{a}$ was "measured" as 10 . However, it is very likely this number would be much higher under the present definition of abrasion. Hooke and others (1985) measured debris transported in conduits under Bondhusbreen over a period of 3 years. They found that the percentage of debris coarser than $0.5 \mathrm{~mm}$ roughly balanced that less than $0.5 \mathrm{~mm}$. It should be proper to infer from this that the percentage of debris finer than $0.66 \mathrm{~mm}$ should be negligible. We will therefore assume that $\dot{q} \gg \dot{a}$ so that $f_{\mathrm{f}} \gg 1$.

There is no field evidence for determining the crossvalley distribution of $f_{f}^{*}$ or $k^{*}$; we shall later present some theoretical arguments for determining their qualitative functional dependency.

\section{The debris-flushing mechanism}

Basal debris flushing will take place primarily at basa $\mathrm{R}$-channels and at $\mathrm{N}$-channels. (We shall include with $\mathrm{N}$-channels pockets created behind bed obstacles by ice separation, provided that the pockets are connected to the fluvial system.) Because $\mathbf{R}$-channels move with the ice, debris can only reach them by channel melting. Melt rates can have a wide range but are typically several meters/year (Shreve, 1972). If the separation distance of major $\mathrm{R}$-channels (with high melt rates) is at least $300 \mathrm{~m}$ and of minor channels (with low melt rates) at least $50 \mathrm{~m}$, which is probably low, it is seen that most basal debris would exis for many years before encountering an R-channel Stationary bedrock $\mathrm{N}$-channels should be the primary initial route of debris evacuation. These $\mathrm{N}$-channels could very well connect with $\mathrm{R}$-channels, so that major $\mathrm{R}$-channels could perform the final evacuation of debris from the glacier.

$\mathrm{N}$-channel debris flushing is essentially the melting out of debris as ice flows over the channel. In addition, there is the effect of "rejection" of particles from the ice face which is enhanced by low channel pressure. This second mechanism has not been studied, but Vivian (1980) noted the rejection of particles from the ice face in a natura cavity beneath Glacier d'Argentière. Hallet (personal communication) estimated these rejection rates to be of order $1 \mathrm{~cm} / \mathrm{d}$. The melting mechanism is a continuously moving version of the $\mathbf{R}$-channel analysis (Shreve, 1972; Nye, 1976). High-summer channel melt rates of order $10-100 \mathrm{~m} / \mathrm{a}$ could easily melt out all surface debris to a depth of centimeters in passing over one $\mathrm{N}$-channel, assuming a typical transit time of $1 \mathrm{~d}$. This suggests that basal debris concentration could oscillate annually, reaching a minimum at the end of the summer melt season.

It is difficult to imagine how large rocks could be removed from ice by $\mathrm{N}$-channel flushing unless the channel alignment was close to the direction of ice motion. (There would be no difficulty in removing large rocks at R-channels.)

We have argued that normally the fluvial flushing factor $f_{\mathrm{f}}$ is large. In order to judge later results, it is essential that we have some idea of the qualitative nature of the functional dependence of $f_{\mathrm{f}}$. The debris-flushing rate

$$
\dot{f}=\dot{q}-\dot{a}=\left(f_{\mathrm{f}}-1\right) \dot{a}=\left(f_{\mathrm{f}}-1\right) k_{\mathrm{a}} c u_{\mathrm{b}}^{2}=f_{\mathrm{f}} k_{\mathrm{a}} c u_{\mathrm{b}}^{2}
$$

from Equations (4) and (3). For both $\mathrm{R}$ - and $\mathrm{N}$-channel flushing, it may be assumed that $f$ be proportional to $c$; Equation (10) satisfies this requirement if $f_{\mathbf{f}}$ is independent of $c$.

Assuming that $\mathrm{N}$-channel flushing is the dominant mechanism, $f$ should depend upon the ratio $\mathrm{N}$-channel projected area/bed area. This ratio can be written as the dimensionless parameter $d / D$, where $d$ and $D$ are, respectively, average $\mathrm{N}$-channel diameter and average $\mathrm{N}$-channel spacing along a stream line. It is reasonable that, for the normal range of parameters, $f$ depends linearly on $d / D$. $\quad \vec{f}$ would also depend on the average N-channe diameter $d$. Thus, if $d$ is very small, no flushing will take place. We will not consider this dependency explicitly and shall assume that $\dot{f}$ is not significantly affected by variation in $d$ across a particular valley.

There is also a velocity dependency for $\dot{f}$. When $u_{\mathrm{b}}=0$, erosion ceases and $f=0$. At very high $u_{\mathrm{b}}$, the transit time over $\mathrm{N}$-channels is so small that $\mathrm{N}$-channel flushing stops; R-channel flushing will dominate. At low $u_{\mathrm{b}}$, there should be a linear relationship between $f$ and the flux crossing the boundary of an $\mathrm{N}$-channel. (Channel alignment does not affect this result, although at high $u_{\mathrm{b}}$ channel alignment can become important.) It follows that at intermediate $u_{\mathrm{b}}$ the velocity dependence of $f$ should be weak.

Thus, assuming $f_{\mathrm{f}} \gg 1$ in Equation (10), $f_{\mathrm{f}}$ should be modelled adequately by relations of the forms

$$
f_{\mathrm{f}} \sim \frac{d}{D} \frac{1}{u_{\mathrm{b}}} \quad \text { or } \quad F_{\mathrm{f}}=D^{*} \frac{1}{U_{\mathrm{b}}}
$$

at low $u_{\mathrm{b}}$ and

$$
f_{\mathrm{f}} \sim \frac{d}{D} \frac{1}{u_{\mathrm{b}}^{2+B}} \quad \text { or } \quad F_{\mathrm{f}}^{*}=D^{*} \frac{1}{U_{\mathrm{b}}^{2+B}}
$$

where $\beta=0$, at intermediate values of $u_{\mathrm{b}}$. Here $D^{*}$ is the ratio of the values of $d / D$ at the arbitrary state and the reference state.

In review, our picture of debris flushing is that, on average, large entrained clasts must first be broken and abraded into smaller fragments which can be effectively removed from the ice face at $\mathrm{N}$-channels. $\mathrm{R}$-channel flushing is of secondary importance. Having assumed that $f_{\mathbf{f}} \gg 1$, the flushing rate $\left(f_{\mathrm{f}}-1\right) \dot{a}$ or $\left(1+1 / f_{\mathrm{f}}\right) \dot{q}$ can be written approximately as $\dot{q}$ and the bedrock erosion rate as $\dot{e}=\dot{q}$. Thus, the quarrying, erosion, and flushing rates are approximately equal.

\section{Quarrying coefficient, $k_{\text {}}$}

As noted previously, time-averaged effective pressure $P_{E}$ may decrease towards the margin and this effect would be pronounced if open-channel flow is pervasive. Rothlisberger and Iken (1981) presented a quarrying mechanism which operates when relatively small pressure fluctuations are superimposed on a low effective pressure (bed-water pressure close to the overburden pressure). Thus, their mechanism becomes more effective as $P_{\mathrm{E}}$ decreases. Because, from Equation (6b), the effect of any quarrying mechanism which is not solely dependent on $u_{\mathrm{b}}$ is contained in the parameter $k_{\mathrm{q}}$, dimensionless $K_{\mathrm{q}}^{*}$ in 
Equations ( $\left.7^{\prime}\right),(8)$, and (9) should increase towards the margin in order to reflect the pressure-fluctuation effect.

\section{Cross-valley relationships}

Our initial example will be a consideration of the variation of the linear debris-influenced axial-independent sliding law in Equations (1") or (8), across a given glacier valley. The best approach appears to be to prescribe the cross-valley bed-erosion rate and basal debris distribution, then solve for the $F_{*}^{*}$ and $K_{0}^{*}$ cross-valley distributions to see if those are reasonable. We shall assume that $K_{2}^{*}=K_{a}^{*} \equiv 1$ as previously discussed, and that $K_{1}^{*}$ may decrease from unity at the center to something more than one-half at the margin.

Present cross-valley profiles provide useful information concerning past erosion rates. If we assume that, for a particular valley, the present-day erosion-rate distribution is the same as the time-averaged past distribution, we obtain a condition on certain coefficients in Equations (8) and (9). A reasonable assumption is that the cross-valley erosion rate $\dot{e}$ is uniform (see Appendix). From Equation (6b), with $\dot{e}=\dot{q}$, the dimensionless erosion-rate distribution is

$$
\dot{E}=K_{\mathrm{q}}^{*} U \text { b. }
$$

Therefore, for this example, with $\dot{E} \equiv 1$

$$
K_{\mathrm{q}}^{*}=U_{\mathrm{b}}{ }^{-\gamma} \text {. }
$$

Equation (12') should not be interpreted as saying that $K_{\mathrm{q}}^{*}$ is determined solely from $U_{\mathrm{b}}$ but simply that the cross-valley variation in $K_{q}^{*}$ and $U_{\mathrm{b}}$ satisfies Equation $\left(12^{\prime}\right)$, if we require that $\dot{E} \equiv 1$.

With $\gamma>0$, Equation $\left(12^{\prime}\right)$ requires an increase in $K_{\mathrm{q}}^{*}$ from center to margin. This agrees qualitatively with our previous analysis of the physics controlling $k_{\mathrm{g}}$. Because $U_{\mathrm{b}}$ decreases by an order of magnitude from center to margin, unless the pressure-fluctuation effect (and other factors affecting $k_{\mathrm{q}}$ ) have a very large cross-valley variation, we must conclude that $y$ is small. Certainly $y=1$ should be considered large. Nothing more concrete can be provided by this analysis until experimental and field work have been done on the various factors affecting quarryability.

The second condition we might apply is to prescribe the cross-valley distribution of debris concentration $c$. It might be possible to estimate this distribution by field work but this has not been done. On the other hand, data which do exist do not suggest any large cross-valley variation in $c$ (personal communication from B. Hallet). On this basis, but more as an example, we can assume that $C \equiv 1$. Equations (9) and $\left(12^{\prime}\right)$ now give

$$
F_{\mathrm{f}}=\overrightarrow{U_{\mathrm{b}}}
$$

This is in agreement with Equation (11'), if $B=0$ and $D^{*} \equiv 1$. Thus the results satisfy all the qualitative restrictions which we have specified.

Equations (1") and (8) now become

$$
T_{\mathrm{b}}=r K_{1}^{*} U_{\mathrm{b}}+(1-r) U_{\mathrm{b}} .
$$

This can be interpreted as a sliding law for cross-valley variations in axial-independent flow. The result is not surprising and speaks for itself.

The more interesting results for this example are contained in Equations (12') and (13). The later result implies that the ratio quarrying rate/abrasion rate increases by about two orders of magnitude from center to margin. It would be possible to check such a result by sampling basal debris at various locations.

The "reasonable results" obtained for this example appear to depend on the quarrying coefficient, $k_{\mathrm{g}}$, in Equation (6b) being non-constant - in this example, satisfying Equation (12') with $y>0$. This is a strong indication that the quarrying law is not solely velocity-dependent. If we had set $K_{\mathrm{q}}^{*} \equiv 1$, instead of requiring $\dot{E} \equiv 1$, Equation $\left(12^{\prime}\right)$ would have been replaced by

$$
\dot{E}=U_{b}^{q}
$$

which, for any $\gamma>0$, would imply a bed-erosion rate decreasing towards the margin. Equation (9) would then yield

$$
K_{\mathbf{f}}=U_{\mathrm{b}}^{q-2}
$$

which is acceptable within the restriction of Equation (11'), if $\gamma$ is small. It is interesting that, again, the sliding law in Equation (14) is obtained because Equation (1") is unaffected, since $C \equiv 1$. Thus, provided $\gamma$ is small, various bed-erosion-rate profiles can be accommodated by the same sliding law while satisfying the restrictions of the model.

\section{Parameter variations}

We consider the effect of variations in parameters $k_{\mathrm{q}}$ $k_{\mathrm{a}}$, and $f_{\mathrm{f}}$ relative to a reference state. Parameters $K_{1}$ and $K_{2}$ will be fixed. The parameter changes could represent changes on a given glacier bed or a comparison among various glacier beds. We will assume that $F_{f}$ is governed by the simple law given by Equation (11') with $B=0$, Thus, $u_{\mathrm{b}}$ will be restricted to the range of intermediate values where this law is appropriate.

Substituting Equation (11') into Equation (9) gives

$$
C=\frac{K_{\mathrm{q}}^{*} U_{\mathrm{b}}^{q}}{D^{*} K_{\mathrm{a}}^{*}} \text {. }
$$

The debris concentration is now velocity-dependent. The fact that $C$ increases with increasing $k_{\mathrm{q}}$ and decreasing $k_{\mathrm{a}}$ and $d / D$ is reasonable. Making the usual assumption that $f_{\mathrm{f}} \gg 1$, the dimensionless bed-erosion rate $\dot{E}$ is still given by Equation (12) and the "relative" sliding law, from Equation (1") is now

$$
T_{\mathrm{b}}=r U_{\mathrm{b}}+\frac{(1-r) K_{\mathrm{q}}^{*}}{D^{*} K_{\mathrm{a}}^{*}} U_{\mathrm{b}}^{\gamma+1}
$$

which exhibits a stronger velocity-dependence in the debrisdrag term than Equation (14).

Several observations can be made. Whereas a change in $k_{\mathrm{a}}$ does not affect the erosion rate (because $\dot{q} \gg \dot{a}$ ), it does affect the debris-drag term. The reason is that the debris concentration varies inversely with $k_{\mathrm{a}}$ from Equation (17). It follows from Equation (17) that large basal debris concentrations would tend to exist where rock is easily quarried but difficult to abrade - thus, hard well-jointed rock. Such a condition could easily result in dense basal debris and could, over time, produce a basal debris layer. (Of course, the analysis of such a time-dependent situation lies outside a sparse debris model.) Parameter $\gamma$ is still undetermined but is expected to be less than one.

\section{Axial-dependent debris balance}

We now consider the effect of step-function changes in $k_{\mathrm{q}}, k_{\mathrm{a}}$, and $f_{\mathrm{f}}$ on the axial-debris distribution. Mass continuity of the debris slab requires that

$$
\delta \frac{\mathrm{d}}{\mathrm{d} x}\left(u_{\mathrm{b}} c\right)=\dot{q}-\dot{a}-\dot{f} .
$$

For convenience, we assume that the basal debris consists of cubical elements where $\delta \equiv$ length of the side of the average element. Again, $\dot{q}$ and $\dot{a}$ are given by Equations (6b) and (3). Fluvial flushing rate $f$, which has only been modelled qualitatively by Equations (10) and (11'), will be assumed to satisfy

$$
\dot{f}=f_{\mathrm{f}} c u_{\mathrm{b}}^{\text {? }}
$$

with $U_{b}^{*} \equiv 1, F_{\mathrm{f}}^{*}=D^{*}$ from Equation $\left(11^{\prime}\right)$. (Note that in the present study, with $u_{\mathrm{b}}$ being held constant, the exponent $\gamma$ in Equation (20), which, from Equations (11) and (11) varies with the range of velocity, will not affect the results.)

It is convenient to express Equation (19) in dimensionless form. We define $\xi=x / h$ where $h$ is ice thickness. This will be considered to be uniform in this development. Also, 
$u_{\mathrm{b}}=u_{\mathrm{bi}} U_{\mathrm{b}}, \quad c=c_{\mathrm{i}} C, \quad k_{\mathrm{q}}=k_{\mathrm{qi}} K_{\mathrm{q}}^{*}, \quad k_{\mathrm{a}}=k_{\mathrm{ai}} k_{\mathrm{a}}^{*}, \quad f_{\mathrm{f}}=f_{\mathrm{fi}} F_{\mathrm{f}}^{*}$ where subscripts i refer to the initial values, at $x=0$, of
the various quantities. Substituting into Equation (19), dividing by $\dot{a}=c_{\mathrm{i}} k_{\mathrm{ai}}\left(u_{\mathrm{bi}}\right)^{2}$, results in

$$
\begin{gathered}
\left(\frac{\delta}{h_{\mathrm{i}} k_{\mathrm{ai}} u_{\mathrm{bi}}}\right] \frac{\mathrm{d}}{\mathrm{d} \xi}\left(C U_{\mathrm{b}}\right)=\left[\frac{\dot{q}_{\mathrm{i}}}{\dot{a}_{\mathrm{i}}}\right] K_{\mathrm{q}}^{*} U_{\mathrm{b}}^{\gamma}- \\
-\left[\frac{\dot{f_{\mathrm{i}}}}{\dot{a} \mathrm{i}}\right] F_{\mathrm{f}}^{*} C U_{\mathrm{b}}^{\gamma}-C K_{\mathrm{a}}^{*} U_{\mathrm{b}}^{2}
\end{gathered}
$$

where $\dot{a}_{\mathrm{i}}, \dot{q}_{\mathrm{i}}, \dot{f}_{\mathrm{i}}$ are the initial values of $\dot{a}, \dot{q}$, and $\dot{f}$ which may be calculated from Equations (3), (6b), and (20), respectively.

We assume that axial-independent flow exists for $x<0$. Therefore, Equation (4) applies there as do the inequalities

$$
\dot{q}>\dot{f} \gg \dot{a}, f_{\mathrm{f}} \gg 1, \text { on } x<0 .
$$

The inequalities $\dot{q}_{\mathrm{i}}>\dot{f}_{\mathrm{i}} \gg \dot{a}_{\mathrm{i}}$ therefore apply in Equation (21). We may therefore neglect the last term in Equation (21). Define

$$
\eta=\delta / h_{\mathrm{i}} k_{\mathrm{ai}}{ }^{u_{\mathrm{bi}}}
$$

so that Equation (21) becomes

$$
\eta \frac{\mathrm{d}}{\mathrm{d} \xi}\left(C U_{\mathrm{b}}\right)=\left[\frac{\dot{q}_{\mathrm{i}}}{\dot{a}_{\mathrm{i}}}\right] K_{\mathrm{q}}^{*} U_{\mathrm{b}}^{\gamma}-\left[\frac{\dot{f}_{\mathrm{i}}}{\dot{a}_{\mathrm{i}}} F_{\mathrm{f}}^{*} C U_{\mathrm{b}}^{\gamma} .\right.
$$

We consider the following problem: with $u_{\mathrm{b}}$ held constant in the axial direction, $U_{\mathrm{b}} \equiv 1$, allow step-function changes in $k_{\mathrm{q}}$ and/or $f_{\mathrm{f}}$ so that $K_{\mathrm{q}}^{*}$ and $F_{\mathrm{f}}^{*}$ are constants, with at least one value not equal to unity, to the right of $\xi=0$. The solution to this problem is

$$
C=\left(1-K_{\mathrm{q}}^{*} / F_{\mathrm{f}}^{*}\right) \exp \left[-\frac{f_{\mathrm{f}}}{\eta} F_{\mathrm{f}}^{* \xi}\right]+\frac{K_{\mathrm{q}}^{*}}{F_{\mathrm{f}}^{*}}, \quad \xi \geqslant 0 .
$$

Here, $f_{\mathrm{f}}=\dot{q}_{\mathrm{i}} / \dot{a}_{\mathrm{i}}$ is the axial-independent fluvial flushing factor which applies on $\xi<0$. The initial conditions satisfied by Equation (24), at $\xi=0^{-}$are $C_{i}=K_{\mathrm{ai}}^{*}=F_{\mathrm{fi}}^{*}=$ 1. The initial condition satisfied at $\xi=0^{+}$is $C_{\mathrm{i}}=1 . K_{\mathrm{Q}}^{*}$ and $F_{f}^{*}$ are constant on $\xi>0$.

The response of the bed to a change in $k_{\mathrm{g}}$ and/or $f_{\mathrm{f}}$ is apparent. $C$ changes exponentially and approaches the new axial-independent value $C=K_{\mathrm{a}}^{*} / F_{\mathrm{f}}^{*}$ asymptotically, as expected. the distance $\Delta \xi$ over which $C$ undergoes $63 \%$ of this adjustment is

$$
\Delta \xi=\frac{\eta}{f_{\mathbf{f}} F_{\mathrm{f}}^{*}}
$$

We may estimate $n$ in Equation (23). Substituting for $k_{\text {ai }}$ from Equation (3) gives the form

$$
\eta=\frac{\delta c_{\mathrm{j}} u_{\mathrm{bi}}}{h_{\mathrm{i}} \dot{a}_{\mathrm{i}}}
$$

Note that $k_{\mathrm{a}}$ in Equations (3) and (23) is not really a laboratory-measured attritivity coefficient but, rather, an effective attritivity coefficient. Because a clast is not in contact with the bed for a large percentage of time, any physical attritivity coefficient must be reduced by this percentage in arriving at the effective attritivity coefficient. Thus, the form in Equation $\left(23^{\prime}\right)$ is preferred. Taking $\delta=$ $10 \mathrm{~cm}, \quad c_{\mathrm{i}}=0.25, \quad u_{\mathrm{bi}}=75 \mathrm{~m} / \mathrm{a}, \quad h_{\mathrm{i}}=150 \mathrm{~m}, \quad \dot{a}_{\mathrm{i}}=0.001$ $\mathrm{mm} / \mathrm{a}$ gives $\eta=4.9 \times 10^{4}$. The value of $\dot{a}_{\mathrm{i}}$ is subject to the most uncertainty. Kjelsen (1983) measured the erosion rate of three Norwegian glaciers to be about $0.1 \mathrm{~mm} / \mathrm{a}$, averaged over the entire bed. Our definition of abrasion requires that $\dot{a}_{\mathrm{i}} / \dot{e}_{\mathrm{i}} \ll 1$, so that we assumed $\dot{a}_{\mathrm{j}} / \dot{e}_{\mathrm{i}}=0.01$.

If we take $f_{\mathrm{f}} F_{\mathrm{f}}=100$ in Equation (25), we obtain $\Delta \xi=490$ or $\Delta x=73 \mathrm{~km}$. Thus, the glacier bed responds very slowly to local changes in quarryability and the fluvial flushing factor. This result lends credibility to our treatment of the discrete processes of flushing, quarrying, and abrasion as continuous processes. It also suggests the assumption that $c$ is constant along a stream line should be reasonable.

There is little possibility that $\Delta x$ values of order $h$ can be achieved in any realistic situation. From Equation (23), it is tempting to consider large values of $u_{b_{i}}$. But even a factor of 10 increase would not be sufficient; moreover, as $u_{\mathrm{b}_{\mathrm{i}}}$ increases, $k_{\mathrm{ai}}$ (effective attritivity) will decrease. Of course, our estimate of $\dot{a}_{i}$ could be low by a factor of 10. Combinations of all these factors might conceivably reduce $\Delta x$ to order $h$.

\section{CONCLUSION}

The modification of any sliding law to include debris-drag term involves the introduction of a debrisconcentration multiplicative factor which, in general, is unknown. But, it appears from our analysis that things are not as bad as they usually are in glaciology. The assumption that $c$ is uniform over the glacier bed appears to be reasonable. The debris-drag term, for the case of sparse debris, then takes a very simple form.

Vivian (1980) observed that a localized high concentration of debris can "spectacularly" increase the shear stress locally. Such localized affects are, of course, averaged over a large area in the present model. It is within this context that the assumption of uniform basal debris concentration applies.

By employing dimensionless forms, we were able to reach conclusions involving relative changes in various parameters, as well as $c$. However, because values of the various parameters are unknown, it is not possible at this stage to compute $c$ (or $r$ ) in the debris-influenced sliding law. Theoretically, if the parameters were known, $c$ could be computed for a particular bed from debris-balance considerations. At the present time, the inverse process appears to be in order; measure $c$ and thus infer something about one or more parameters.

By our assumptions, the erosion rate is practically identical to the quarrying rate. A rudimentary quarrying law has been proposed which depends weakly on sliding velocity and to the same extent on other factors such as the effective pressure-pressure-fluctuation mechanism. A proposed fluvial debris-flushing law is even more rudimentary.

Whereas spatial variations in $c$ may be small or negligible, the same may not be true of time variations as observed by Hooke and others (1985). R-channel debris flushing should virtually cease during the non-melt season. The same will not be true for $\mathrm{N}$-channel flushing, which we have assumed is the dominant flushing route. But melt rates at $\mathrm{N}$-channels will be reduced during the winter, perhaps by an order of magnitude, but at least by 2 or 3 times. Thus, there could be a build-up in small debris particles during the winter which are flushed out in the spring. It is possible that debris drag could oscillate annually by a ratio of, perhaps, 2 . This could account for a significant annual oscillation in sliding velocity.

\section{ACKNOWLEDGEMENTS}

The writer thanks the NSERC of Canada for support and $\mathrm{Mr} \mathrm{V}$. $\mathrm{Ng}$ for performing the computations. I did not hesitate to call B. Hallet on frequent occasions and I benefited greatly from his comments on an early version of the manuscript.

\section{REFERENCES}

Bindschadler, R. 1983. The importance of pressurized subglacial water in separation and sliding at the glacier bed. Journal of Glaciology, Vol. 29, No. 101, p. 3-19. 
Bindschadler, R., and others. 1977. Geometry and dynamics of a surge-type glacier, by $\mathbf{R}$. Bindschadler, W.D. Harrison, C.F. Raymond, and R. Croisson. Journal of Glaciology, Vol. 18, No. 79, p. 181-94.

Boulton, G.S. 1979. Processes of glacier erosion on different substrata. Journal of Glaciology, Vol. 23, No. 89, p. 15-38.

Clarke, G.K.C., and Goodman, R.H. 1975. Radio echo sounding and ice-temperature measurements in a surge-type glacier. Journal of Glaciology, Vol. 14, No. 70, p. 71-78.

Davis, J.L., and others. 1973. Radio echo sounding on a valley glacier in East Greenland, by J.L. Davis, J.S. Halliday, and K.J. Miller. Journal of Glaciology, Vol. 12, No. 64, p. $87-91$

Doornkamp, J.C., and King, C.A.M. 1971. Numerical analysis in geomorphology. London, Edward Arnold.

Gutenberg, B., and others. 1956. Seismic explorations on the floor of Yosemite Valley, California, by B. Gutenberg, J.P. Buwalda, and R.P. Sharp. Bulletin of the Geological Society of America, Vol. 67, p. 1051-78.

Hallet, B. 1979[a]. A theoretical model of glacial abrasion. Journal of Glaciology, Vol. 23, No. 89, p. 39-50.

Hallet, B. 1979[b]. Subglacial regelation water film. Journal of Glaciology, Vol. 23, No. 89, p. 321-24.

Hallet, B. 1981. Glacial abrasion and sliding: their dependence on the debris concentration in basal ice. Annals of Glaciology, Vol. 2, p. 23-28.

Hooke, R.L. 1984. On the role of mechanical energy in maintaining subglacial water conduits at atmospheric pressure. Journal of Glaciology, Vol. 30, No. 105, p. 180-87.

Hooke, R.L., and others. 1985. Subglacial hydrology and sediment transport at Bondhusbreen, southeast Norway, by R.L. Hooke, B. Wold, and J.O. Hagen. Geological Society of America. Bulletin, Vol. 96, p. 388-97.

K jeldsen, O. 1983. Materialtransportundersøkelser i norske breelver 1981. Norges Vassdrags-og Elektrisitetsvesen. Vassdragsdirektoratet. Hydrologisk Avdeling. Rapport, $\mathrm{Nr}$. $1-83$.

Lliboutry, L. 1979. Local friction laws for glaciers: a critical review and new openings. Journal of Glaciology, Vol. 23 , No. 89 , p. 67-95.

Løken, O.H., and Hodgson, D.A. 1971. On the submarine geomorphology along the east coast of Baffin Island. Canadian Journal of Earth Sciences, Vol. 8, No. 2, p. $185-95$.

Matthes, F.E. 1930. Geologic history of the Yosemite Valley. U.S. Geological Survey. Professional Paper 160.

Metcalf, R.C. 1979. Energy dissipation during subglacial abrasion at Nisqually Glacier, Washington, U.S.A. Journal of Glaciology, Vol. 23, No. 89, p. 233-46.

Morgan, V.I., and Budd, W.F. 1975. Radio-echo sounding of the Lambert Glacier basin. Journal of Glaciology, Vol. 15, No. 73 , p. 103-11.

Nye, J.F. 1976. Water flow in glaciers: jokulhlaups, tunnels and veins. Journal of Glaciology, Vol. 17, No. 76, p. 181-207.
Pickard, G.L. 1956. Physical features of British Columbia inlets. Transactions of the Royal Society of Canada, Vol. 50 , Ser. 3, p. 47-58.

Raymond, C.F. 1971. Flow in a transverse section of Athabasca Glacier, Alberta, Canada. Journal of Glaciology, Vol. 10, No. 58, p. 55-84.

Röthlisberger, H., and Iken, A. 1981. Plucking as an effect of water-pressure variations at the glacier bed. Annals of Glaciology, Vol. 2, p. 57-62.

St. John, R.W. Unpublished. Interpretation of seismic profiles of Howe Sound. [B.Sc. thesis, University of British Columbia, 1972.]

Shreve, R.L. 1972. Movement of water in glaciers. Journal of Glaciology, Vol. 11, No. 62, p. 205-14.

Vivian, R. 1980. The nature of the ice-rock interface: the results of investigation on $20000 \mathrm{~m}^{2}$ of the rock bed of temperate glaciers. Journal of Glaciology, Vol. 25, No. 92, p. 267-77.

Weertman, J. 1957. On the sliding of glaciers. Journal of Glaciology, Vol. 3, No. 21, p. 33-38.

Weertman, J. 1964. The theory of glacier sliding. Journal of Glaciology, Vol. 5, No. 39, p. 287-303.

\section{APPENDIX}

Table I presents half-width/depth $(w / 2 h)$ data for various glacier and fjord valleys. The valleys are ordered according to increasing size. Most data come from seismic or radio-echo profiles. Where this is not the case, for certain fjords, bathymetric profiles were used only if the bedrock profile was evident.

It is clear that the data do not substantiate the common assertion that glacial erosion serves mainly to deepen a pre-existing river valley with, presumably, little erosion of the margins. If this assertion were true, $w / 2 h$ values would generally decrease down the column of Table as the extent of glacial erosion increases. Moreover, the assertion implies that $w / 2 h$ values should be less than unity for valleys which have undergone very extensive glacial erosion, such as the valleys of Fisher and Lambert Glaciers.

We note that the inequality $w / 2 h>1$ does not, by itself, ensure that erosion rates increase towards the margin. This is because the shape of the pre-glacial valley must be considered when estimating glacial erosion. For example, Matthes (1930) has given an illustration of pre-glacial profiles of Yosemite Valley. If glacial erosion is computed relative to his illustrated profile, the ratio of margin/centreline erosion rate $\left(\dot{e}_{\mathrm{m}} / \dot{e}_{\mathrm{c}}\right)$ would be about 0.7 , instead of the value 1.0 as inferred from Table $I$, at the two narrow sections for which seismic data exist. But, because many of the $w / 2 h$ values of Table I greatly exceed unity, there are at least some cases (probably the majority) where $\dot{e}_{\mathrm{m}} / \dot{e}_{\mathrm{c}}>1$.

Another method of analysis is to assume that, for all time after major glacier erosion has occurred, a valley profile is quadratic with a fixed shape (Doornkamp and King, 1971). Thus, during this time $w / 2 h$ is fixed. It is easily

TABLE I

Glacier

Rusty Glacier Athabasca Glacier

Variegated Glacier

Roslingletscher

Gardner Inlet

Jervis Inlet

Howe Sound

Yosemite Valley

Inugsuin Fjord

Fisher Glacier

Lambert Glacier

$w / 2 h$ range
$4-5.8$
$2 \ddagger$
$1.1-2.2$
$2.8-3.4$
$1.1-2.1$
$1.4-2.0$
$1.3-5.8^{*}$
$17^{*}$
$5.1-8.2$
$6 \ddagger$
$10 \ddagger$

*Most values exceed 2.5 .

+Only two profiles available at narrows. More typical $w / 2 h$ values would certainly exceed unity.

$\ddagger$ Only one profile available.

\section{Reference}

Clarke and others (1975)

Raymond (1971)

Bindschadler and others (1977)

Davis and others (1973)

Pickard (1956)

Pickard (1956)

St. John (unpublished)

Gutenberg and others (1956)

Løken and Hodgson (1971)

Morgan and Budd (1975)

Morgan and Budd (1975) 
shown that, provided $w / 2 h>\sqrt{2}, \dot{e}$ is minimum on the center line and increases monotonically towards the margin. If $w / 2 h>\sqrt{4 / 3}, \dot{e}_{\mathrm{m}}>\dot{\mathrm{e}}_{\mathrm{c}}$ but $\dot{e}$ does not everywhere increase monotonically from center to margin. In this purely geometric analysis $\dot{e}$ is measured normal to the profile.

One of the referees has objected to the conclusion that $\dot{e}$ increases from center to margin, citing the following reasons: (1) The larger glacier fjord valleys empty into the sea and floating effects would reduce erosion at depth. (2)
Quarrying at depth might be more difficult, since we would expect the degree of jointing to decrease with depth. This effect would cause $w / 2 h$ values to increase at the bottom of Table I. (3) The larger valleys may have formed from adjacent river valleys so that the initial $w / 2 h$ value, before glacial erosion, could have been high. I agree that (2) and (3) consitute reasons for reducing the $w / 2 h$ values towards the bottom of the table. I do not agree with reason (1) but my argument would be lengthy.

MS. received 18 October 1983 and in revised form 25 October 1985 